\title{
Developments in Construction Practices towards Seismic Safety of Structures
}

\author{
Dr. A. K. Sinha ${ }^{1}$ and Sharad Singh ${ }^{2}$
}

\begin{abstract}
Increase in seismic activity in last couple decades around the globe has raised concerns of everyone. Recent development in earthquake resistant techniques shows that the performance of structures can be improved by improving the response of structure to ground motion. Structure can be provided with supplemental damping and stiffness and sometimes even isolated from ground motion, so as to help it in process of response control. But there is need to improve structural designs and material properties like damping and stiffness to make structures self-capable of controlling their response. This paper focuses on both the modes of structural response improvement viz. external elements of response control and structural elements for response improvement. This paper emphasizes the need of innovative materials and techniques towards seismic safety of structures. A brief outline of various concepts has been presented along with their effects on response of structure.
\end{abstract}

Keywords - Response control, Seismic safety, Smart materials, Sustainability and Resiliency

\section{INTRODUCTION}

$\mathrm{P}$ ROTECTING structures against earthquake has always been a challenge to mankind. But with the recent events of highly frequent earthquakes around the globe, the need to save life and property has become more eminent. The seismicity being unpredictable the only solution available is to make structures safer against earthquakes and construct them with a perspective of preventing total collapse. Even with use of good techniques and machines for construction, in the recent past structures have fallen prey to earthquakes. The experiences of past earthquakes have provided sufficient evidences about performance of different structures under various conditions as working ground. The structure is regarded as dynamic system whose response variables are functions of time and the recent developments in earthquake resistant techniques contributes towards response control of structures against the ground motion. The dynamic equation of motion reveals the effects of mass distribution, stiffness and damping on the response behavior of structure under the effect of ground motion. These factors contributing towards the response behavior of the structure can be modified in a structural system either inherently or with external aid to control the structural response and thereby minimizing the dynamic effects of load under an acceptable limit [1].

Dr. A.K. Sinha ${ }^{1}$, Professor, Department of Civil Engineering, National Institute of Technology, Patna, India.

Sharad Singh ${ }^{2}$ Research Scholar, Structural Engineering, Department of Civil Engineering, National Institute of Technology, Patna, India.
It has been well established that the response of the structure to ground motion is by the virtue of its inertia. A proper design methodology in terms of strategic distribution of mass and stiffness is being emphasized upon so as to maintain the integrity of the structure. Where mass and stiffness hold vital role in controlling displacement of the structure relative to ground motion, damping on the other hand is important from the concern to slash the cause of response and dissipate the seismic energy entering the structure. Earlier investigations reveal that under the effect of seismic excitation the response of the structure is viewed in form of two kinds of interaction mechanisms between ground and structure viz. kinematic or dynamic. Under the kinematic interaction effects the response is viewed in terms of inertia of structure against the motion of base due to ground motion, whereas in dynamic interaction it is suggested that the ground motion exhibits direct force on structure and the energy is transferred directly from ground to structure. These response interaction mechanisms are utilized in adopting and designing of earthquake resistant techniques for structures. Based on the two interaction mechanisms there are two modes of response control. Based on kinematic interaction is modification of dynamic characteristics of structure for response control and on the basis of dynamic interaction is modification of energy absorption mode of response control. Where the inertial parameters viz. mass and stiffness follow modification of dynamic character, damping follows modification of energy absorption criteria [1-3].

It is also paramount to understand the mechanism behind the damping phenomenon, as it will be necessary in adopting design and material requirements for structure and accordingly modify its natural damping properties as well as in design of supplemental damping agents. For any structural system under dynamic loading, the entrant energy is dissipated naturally by various damping mechanisms acting simultaneously. The thermal effect of repeated elastic straining, internal friction when solid deforms, friction at joints and opening and closing of micro cracks are the known mechanisms dissipating vibrational energy. As the mathematics of the mechanism behavior in damping is not precisely known, the collective damping phenomenon is idealized as viscous damping within the linear elastic limit of the deformation and estimated by studying the response of the structure. Sometimes damping in structural system is attributed to static hysteresis which is rate independent linear damping and is non-viscous in nature. Apart from viscous damping vibrational energy is also dissipated by macroscopic plastic deformation and yielding of material and even due to 
friction of structural system. This damping is non-linear in nature and observable in the inelastic behavior of the considered structural system. The damping due to friction of the structural system is called as coulomb friction damping. All the damping mechanisms are hysteretic in behavior but with some differences in the hysteresis loop which is dependent on material property [1].

\section{DESIGN PHILOSOPHIES}

For all structures being designed, it is expected to prevent total collapse of the structure. All most all ERD code provisions in various countries have laid down guidelines for earthquake resistant design philosophies for structures, allowing damage to structural elements but no total collapse of the structure. It is known that the earthquake load is a displacement type load, and the force induced in the structure by the virtue of inertia is controlled by mass of the structure. To control displacement under the effect of ground motion, the amplitude response of the structure should be low. The displacement amplitudes resulting from the natural response modes of the structure are dependent on natural time period $T_{n}$ of the oscillation of the structure $[1,4] . T_{n}$ is largely dependent on stiffness $\mathrm{k}$ and mass $\mathrm{m}$ of the structural system as explained by the following relationship (1).

$$
T n=2 \pi \sqrt{\frac{m}{k}}
$$

The effect of $T_{n}$ has been incorporated in design guidelines in terms of $\mathrm{S}_{\mathrm{a}} / \mathrm{g}$ values which is largely described by the nature of soil in which the structure exists. It is of utmost importance to mention that the classification of soil for this purpose is based on SPT value of soil; categorizing it into soft, medium and hard rock; and does not take into account the dynamic behavior of underlying soil strata through which the seismic waves propagate. It is necessary to consider local site effect and take into account soil-structure interaction effect while designing the structure. $T_{n}$ is largely effected by structural configuration both in plan and elevation as well as in terms of mass and stiffness distribution. It has also been investigated by researchers that $T_{n}$ tends to change due to presence of cracked sections.

\section{A.Effect Of Configuration On Seismic Performance Of Structure}

Configuration critically affects the seismic performance of structure. Plan shape, plan aspect ratio, slenderness ratio and the effect of diaphragm action of the structure are important geometrical components to be considered in design. Today several structural systems viz. moment frame systems, braced frame systems, structural wall frame systems and tube systems, have been proved to show reliable performance during earthquake and are being readily adopted. Here it is important to mention that the highly popular flat slab-column system is highly vulnerable to even small ground shaking and even with provision of additional lateral load resisting system, it is recommended to prohibit use of such structural system in practice. Another important issue to be considered in structural design is discontinuity in load paths. A direct load path is required to transfer inertial force generated during structural vibration to the ground. Frames with floating columns, set-backs, lack of grids, overhangs, discontinuing structural walls and structural walls with large openings are causes of discontinuity in load paths.

\section{B. Effect Of Mass And Stiffness}

Mass and stiffness are critical components that guide the traditional ERD philosophy. Uniformity of structure in mass and stiffness is necessary both in plan and elevation. Apart from this the effects of pounding/adjacency is important to be incorporated is construction of any structure.

The above stiffness based design method which considers elastic behavior of the structural system is necessary but not sufficient for ERD. The current practice adopted by most code based design guidelines is to incorporate the effect of inelastic behavior of structural members. This concept of strength based design considers the elastic design formulation of stiffness and mass distribution but mandates provision of sufficient strength to members of structure to simultaneously resist axial force as well as bending moments (P-M interaction mechanism). The strength based design has two philosophies viz. force based design and capacity based design. The capacity based design emphasizes on hierarchy of relative strength in structural members i.e. strong column weak beam concept as well as design for shear is dependent on P-M interaction mechanism and selection of a suitable collapse mechanism; whereas the force based design which does not consider these effects and is only strength based improvement to elastic design and is highly discouraged to prevent heavy damage to structural elements and its total collapse. Even when the structure has resisted seismic load effectively it many a times attracts sufficient deformations permanently causing severe damage. Researchers have developed methods to overcome this situation by considering the inelastic behavior of structure to limit the maximum deformation in any structural member. This improvement in design philosophy over current practice of strength based design follows design for mass and stiffness distribution, strength provision and sufficient ductility to resist deformations and achieve desired collapse mechanism from the view point of formation of plastic hinges. This practice is gaining prominence and codes need to be revised with these specifications. The inelastic behavior is associated with dissipation of input seismic energy by hysteretic inelastic deformation beyond the materials elastic yield point. This concept of meeting structural demand for sufficient provision of energy dissipation capacity popularly known as energy based design is under research and is being looked upon as most reliable design philosophy for better response of structure under effect of earthquake.

\section{Response CONTROL Of StRUCTURAL SyStemS}

Even the best design philosophies are not sufficient in improving the performance of a structure, during ground motion, to desired level. This attracted the need to control the response of structure externally by providing required 
structural properties, which could not be sufficiently provided in structural members. The supplementary structural elements, called the structural response control devices, are based on the similar principles of interaction mechanism between ground and structure. Of all the precautionary measures being adopted for earthquake resistance of structures the most promising measure appears to be response control of structures. The response of structure to ground motion, as mentioned earlier, in terms of interaction mechanisms gives an insight into mode of response control of structure. Based on the two interaction mechanisms there are two modes of response control. Based on kinematic interaction is modification of dynamic characteristics of structure for response control and on the basis of dynamic interaction is modification of energy absorption mode of response control.

\section{A. Modification Of Dynamic Characteristics}

Based on dynamic character modification the structure is isolated from ground motion. Isolation involves decoupling the superstructure from base as such the inertia of structure against ground motion or base movement is controlled. This prevents or limits entrant seismic energy into the superstructure. The structural period of vibration shifts towards lower side of vibration mode to reduce relative amplitude response and avoids resonance with seismic vibration frequency. The resonance of ambient frequency with forcing frequency is catastrophic which is avoided in this mode of response control. It is effective over a limited range of frequencies as seismic excitation is random and contains a sequence of random frequencies. Hence in advance knowledge of frequency content of seismic wave is required for accurate implementation of this mode of response control. In addition to frequency shift due to isolation of base a lateral motion is generated in compensation for frequency shift. As a result the entire structure undergoes rigid body motion horizontally and no inertial force is generated which protects structure against damaging effects.

\section{B. Modification Of Energy Absorption}

Under energy absorption modification the structure is coupled with energy dissipating devices to dissipate entrant seismic energy. The seismic energy is allowed to enter the structure which is consequently shared by energy dissipating devices as such overall load carried by the structure is reduced and hence the response is controlled. Energy is dissipated by damping and inelastic deformations which form the criteria for energy based design of earthquake resistant structure. It is applicable to any range of forcing frequency as accordingly the frequency is distributed in the control system unlike the former mode of frequency shift. The problem of lateral motion generation is eliminated in this mode as such it provides ease and comfort to users. Following the concept of response control via modification of either dynamic characteristic or energy absorption characteristic the earthquake protection systems have been broadly categorized into
1. Base Isolation Systems: This follow the modification of dynamic characteristic.

2. Energy Dissipation System: This is based on modification of energy absorption.

3. Tuned Systems: This incorporates both.

The concept of "Base isolation" is almost a century old. The base isolation is achieved by introduction of low stiffness bearings and dampers between the superstructure and the foundation. Bearings tend to make the combined system more flexible and hence shift its first mode natural frequency away from predominant frequency of earthquake motion, thereby reducing inertial forces and accelerations. The response of isolated structure reduces to $1 / 2$ o $1 / 8$ of the traditional structure. Whereas the dampers provided in the system absorbs energy and prevents entry of seismic energy into the superstructure. Various known isolation systems are roller/ball bearings in foundation, elastomeric bearings, BS cushion isolation, friction Bearings, pendulum systems, spring type systems, rocking systems, and sleeved pile isolation system [14].

Energy dissipation devices (Dampers) follow energy dissipation mechanism based on modification of energy absorption. Several damping mechanism, as stated earlier, are cause for natural structural damping. All these damping mechanisms have been utilized individually or in combination to design and develop various categories of energy dissipating devices stated below. The dampers have been in use for long time but there major application was known only to field of mechanical systems, piping systems, automobiles and aerospace. The application to structural systems to resist wind and earthquake induced vibration has only been known for a couple of decades only after pioneering investigations of Housner on energy balance approach for design procedure. Various types of damping systems in use today are viscoelastic dampers (VED), viscous/fluid viscous dampers (VD/FVD), friction dampers (FD), energy dissipating restraint (EDR), and metallic yielding dampers and extrusion devices [15-20, 22-24].

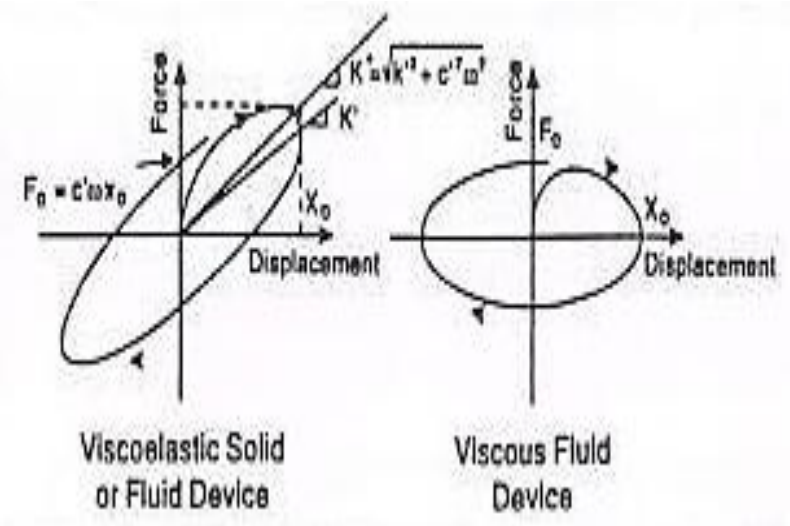



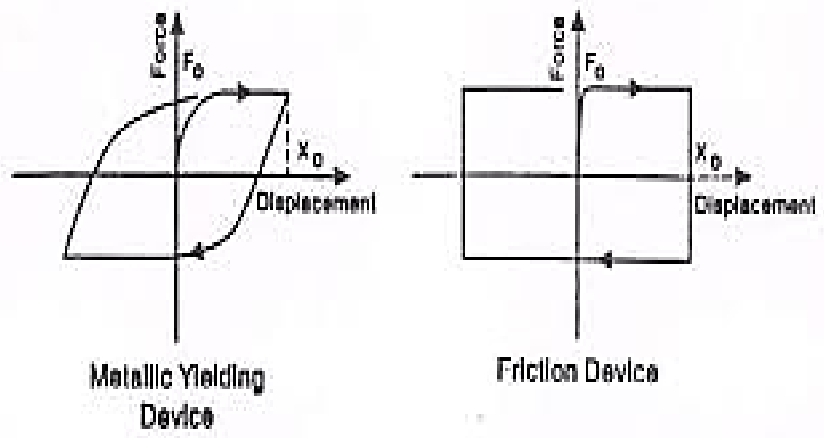

Fig. 1 Generalized hysteretic force-displacement loop for various energy dissipating devices (After: M.C. Constantinou, T.T. Soong, and G.F. Dargush, Passive energy dissipation systems for structural design and retrofit, MCEER, University at Buffalo, NY, 19998, pg no. 10)

With the concept of inertia of a structure under dynamic loading, the structural system can be tuned to vibrate at natural frequency, with additional mass mounted to structure and tuned to natural frequency of vibration of the structure. With the tuned system the structural oscillation is transferred to the mounted mass, which oscillates by the virtue of its inertia against the structural vibration. This opposing oscillation prevents the resonance of the structural vibration with the forcing frequency and thereby restraining to oscillate at its natural frequency. The additional inertial mass to the system can either me a solid or liquid depending upon the arrangement of the tuned system. The transferred kinetic energy is dampened by the tuned system (and in some arrangements additional dampers are provided to aid in with damping process), thus imposing lower energy dissipation requirement on the structure. Developers have categorized tuned systems into tuned mass dampers (TMD), tuned liquid dampers (TLD) and tuned liquid column dampers (TLCD). However the response reduction of any tuned system is dependent on frequency content of external excitation and performs over a set range of frequencies.

These response control devices have capabilities of response reduction, but with advancement in mechanical control system and sensing technology developers have identified to control the operation and behavior of these devices for an optimum performance. Based on operational characteristics following control systems are known viz. passive control systems, active control systems, semi-active control systems and hybrid control systems.

Passive control system as the name suggests are the simplest ones with no significant control system employed to monitor and control the behavior. All the devices mentioned above under the category of isolators and dampers when installed indigenously fall under the category of passive control devices. Active, semi-active and hybrid structural control systems are a natural evolution of passive control technologies. The possible use of active control systems and some combinations of passive, semi-active and active systems, so called hybrid systems, as a means of structural protection against seismic loads has received considerable attention. Active/hybrid control systems are force delivery devices integrated with real-time processing evaluators/controllers and sensors within the structure. They act simultaneously with the hazardous excitation to provide enhanced structural behavior for improved service and safety. Rapid growth of research interest and development of active/hybrid structural control systems is in part due to several coordinated research efforts. Indeed, the most challenging aspect of it in civil engineering is the fact that it's an integration of a number of diverse disciplines, some of which are not within the domain of traditional civil engineering (computer science, data processing, control theory, material science, sensing technology, as well as stochastic processes), with structural dynamics, and wind and earthquake engineering. These coordinated efforts have facilitated collaborative research efforts among researchers from diverse background and accelerated the research-to-implementation process as one sees today. A side benefit of hybrid and semi-active control systems is that, in the case of a power failure, the passive components of the control still offer some degree of protection, unlike a fully active control system [21, 25-26].

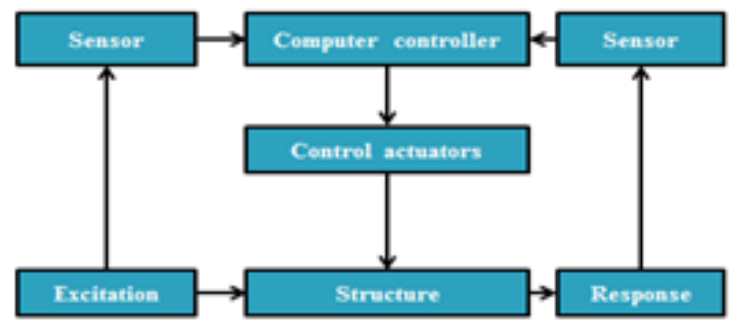

Fig. 2 Active control system (After: B.F. Spencer Jr. T.T. SOONG; New applications and development of active semi-active and hybrid control techniques for seismic and non-seismic vibration in USA; Proceedings Of International Post-Smirt Conference Seminar On

Seismic Isolation, PED \& Active Control Of Vibration Of Structures, Cheju, Korea, 1999)

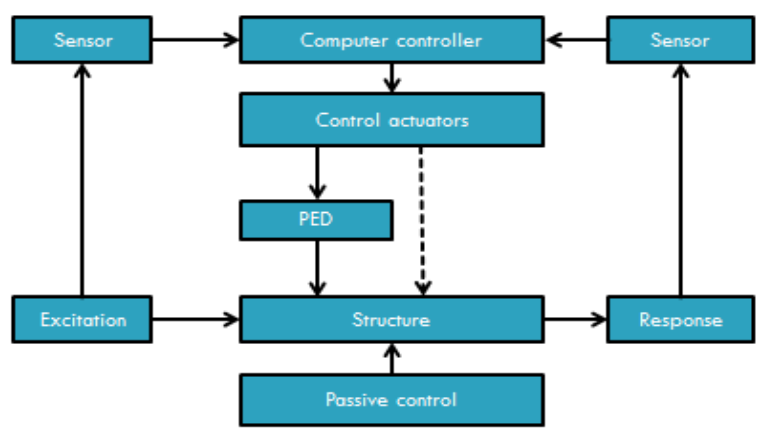

Fig. 3 Hybrid control system (After: B.F. Spencer Jr. T.T. SOONG; New applications and development of active semi-active and hybrid control techniques for seismic and non-seismic vibration in USA;

Proceedings Of International Post-Smirt Conference Seminar On Seismic Isolation, Ped \& Active Control Of Vibration Of Structures, Cheju, Korea, 1999)

\section{REPAIR, RETROFITTING AND SEISMIC STRENGTHENING OF SEISMicAlly Vulnerable STRUCTURES}

Even with good design strategies followed for seismic safety of structures in the aftermath of an earthquake sever damages me occur, thereby degrading the strength of 
structures in both vertical and lateral load carrying capacity. The yielding of structure, cracked sections, failure of structural elements hampers the original stiffness and ductility provisions making structures more vulnerable to future earthquakes as well as immediate vertical load carrying capacity, leading to total collapse. It is necessary to restore and upgrade structures' lateral load resistance and improve its performance for in future earthquakes. Seismic retrofitting is the modification of existing structures to make them more resistant to seismic activity. Mere repair of architectural elements does not make the structure safe against earthquake, thereby necessitating opting for retrofitting and seismic strengthening [7-13]. The main purpose is to provide necessary stiffness and ductility to structural members, adding reinforcements, repairing cracked sections, ensuring proper joint connections, confirmation of symmetry of mass, stiffness and configuration, and re-establishing a required load path. This can be achieved both by internal and/or external modification of structural members as well as by use of elements for response control of structures in association with former requirements.

Understanding the seismic demand on structures and experiences with large earthquakes near urban centers, the need of seismic retrofitting is well acknowledged. Prior to the introduction of seismic codes many structures had been designed without adequate detailing and reinforcement for seismic protection. Various research works has been carried out for the development of the retrofitting codes and guidelines have been published around the world for seismic assessment, retrofit and rehabilitation [7-13, 29].

Retrofitting an existing structure can often be more cost effective than constructing a new facility. Existing structures comprise the largest segment of the built environment. It is important to initiate energy conservation retrofits to reduce energy consumption and the cost of structure. But conserving energy is not the only reason for retrofitting existing structures. If we want to avoid being locked in a bigger carbon footprint for years to come, we need to retrofit the structures in an energy-efficient manner. To do so, we must use the latest technologies to achieve the greatest reductions in emissions and energy consumption. Energy-efficient retrofitting brings many environmental, economic, social and health benefits as well as increases energy security. Designing major renovations and retrofits for existing structure includes sustainability initiatives will reduce operation costs and environmental impacts, and can increase building adaptability, durability, and resiliency. The goal should be to create a highperformance of the structure. A critical difference in the quality and strength of the retrofit occurs with a good retrofit plan. The existing strength of structure, as well as its earthquake vulnerabilities are to be determined, knowing what to do, where to do it, and how to do it are extremely important. It will reduce the risk of both damage to the property and personal injury to its occupants.

\section{Application Of InNovative Materials For Seismic SAFETY OF STRUCTURES}

The seismic performance of structures cannot be improved upon unless the requisite mechanical properties of the constituent materials are ensured to meet desired level of behavior under the effect of seismic load. An approach to enhance the required mechanical properties of materials has led to evolution of various polymers and alloys, Nano materials, and smart materials. Traditional construction materials like brick, stone and clay; concrete of grades; steel rebar and structural steels; wood, glass, ceramics and plastics raise issues of strength, ductility and self-weight. From seismic consideration high ductility is important but strength to self-weight ratio cannot be ignored while arriving to a suitable reinforcing material [29-30].

For a long time steel has been largely used as rebar as well as structural steel in close association with concrete but have high density as such there excessive use in a structure can increase self-weight of structure as well as add to cost of the structure. Apart from these selection of suitable material is also guided by factors like durability, resistance to environmental conditions and sustainability.

Smart materials are the future of construction industry. Ongoing researches and experiments show wide range of applications to structures for better performance in awake of an earthquake. Smart materials have ability to change their physical and mechanical properties in response to specific stimulus input.

Nano- materials like CNT and CNF show better properties compared to traditional steel but manufacturing and cost has limited its application to wider scale.

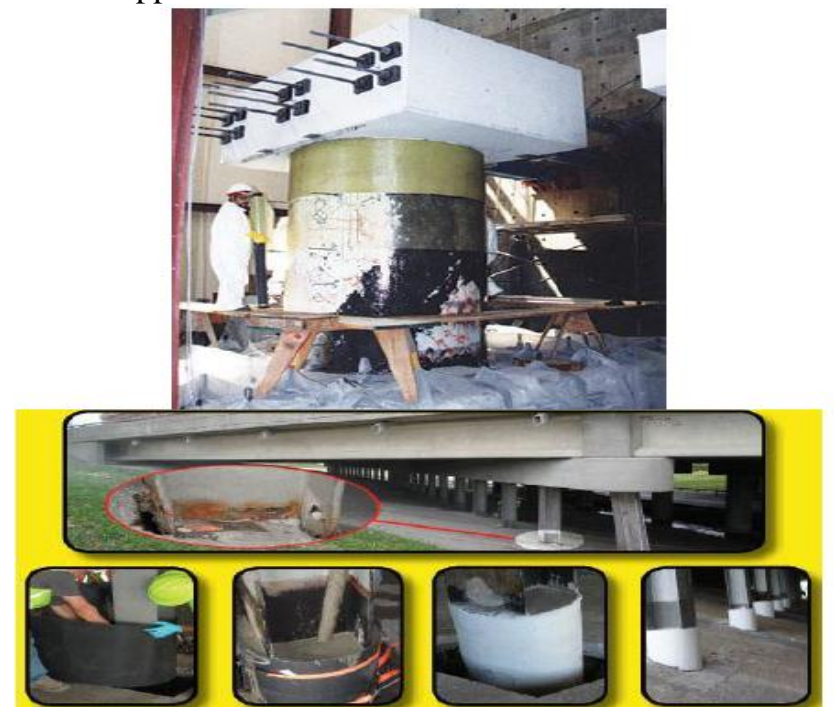

Fig. 4 Seismic retrofitting of a bridge with fiber reinforced polymer sheet (After: Subrata Chandra Das And Md. Enamul Haque Nizam; Application Of FRP Composites In Civil Engineering, International Journal Of Advanced Structures And Geotechnical Engineering, ISSN 2319-5347, Vol 3 No. 3, July 2014, Pg No-306)

It is important to grab attention to the issue and develop similar cost efficient and easy to manufacture Nano-materials. Use of Nano-silica, Nano-Titania, Nano-calcite particles, and 
Nano-clays in concrete has already been taken up. Researchers are also developing self-healing materials with capabilities to repair cracks and deformations and restore the original form of yielded materials, without human intervention.

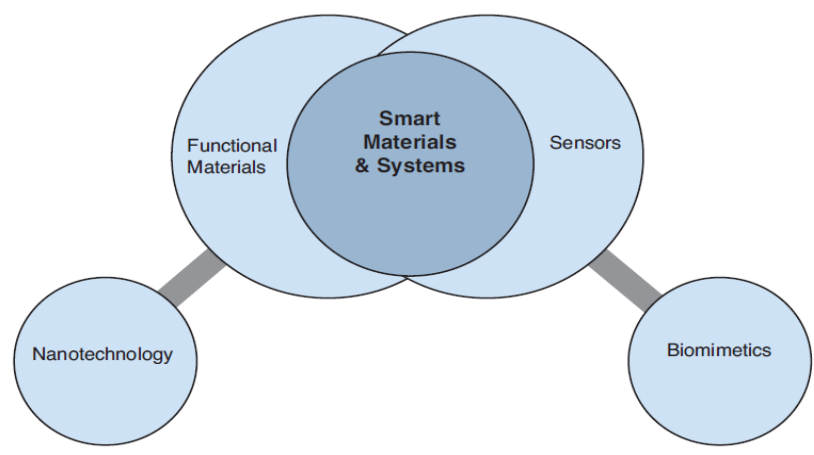

Fig. 5 Smart materials occupy an overlapping technology space (Source: Foresight Smart Materials For $21^{\text {st }}$ Century Report, The Institute Of Materials, Minerals And Mining)

The response control devices mentioned employ use of such materials for high edge performance of structures. Base isolators have been developed using a variety of synthetic rubbers and other polymers like Teflon and Neoprene in layers with steel and supportive materials like lead and bronze to resist base shear. This category of elastomeric bearings is being widely used in form of laminated rubber bearing and New Zealand bearings. Another innovation in isolation is treated Asphalt-Fiber Seismic Base Isolation Cushion, popularly known as BS cushion (Chinese Patent Number ZL99202381.5). in the development of energy dissipation devices a similar form of synthetic rubbers, super plastic materials, high viscosity fluids, viscous solids, magneto-rheological fluids and electro rheological fluids, magneto and electro strictive materials. The advantage of using these materials for energy dissipation devices is in the hysteretic behavior of these materials. The yielding behavior of metals and hysteretic behavior in inelastic range has been used to develop metallic dampers, which are expected to yield before the structural members yield. Various bracing systems using mild steel are known but the most popular advancement in the metallic dampers is added damping and stiffness (ADAS, triangular ADAS, and lead extrusion devices. The issues of post yielding damage and unstable hysteretic behavior under repeated inelastic deformation in metallic yielding dampers has invited the adaption of shape memory alloys and polymers for design of metallic dampers [14-27, 31].

SMAs have uniqueness to undergo phase reversible phase transformation thereby yield repeatedly without acquiring permanent deformation thereby making them most favorable materials for metallic dampers. Various SMAs have excellent fatigue resistance and corrosion resistance. Study on Nitinol (nickel titanium alloy) and Copper-Zinc-Aluminum reveal effective reduction in seismic response under torsional, flexural and axial deformation modes. The application of innovative materials to structures is most popular in development of active and hybrid control systems for seismic response control of structures. The functioning of control systems and their performance using sensors, transducers, actuators and control algorithms is all dependent on precise use of smart and intelligent materials.

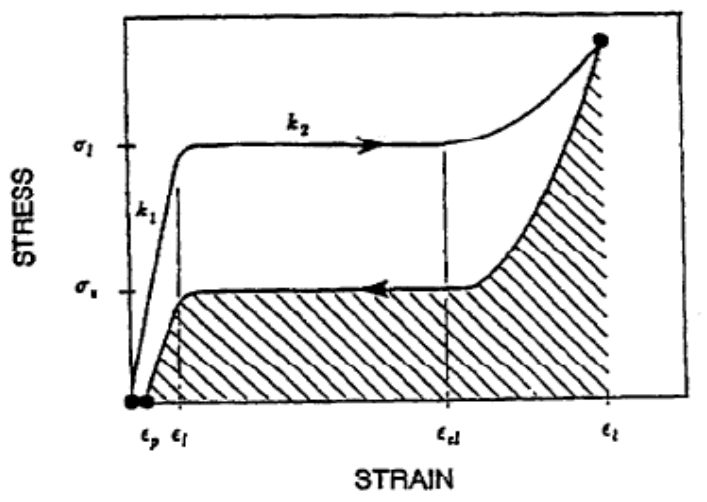

Fig. 6 Super-elastic behavior of SMA
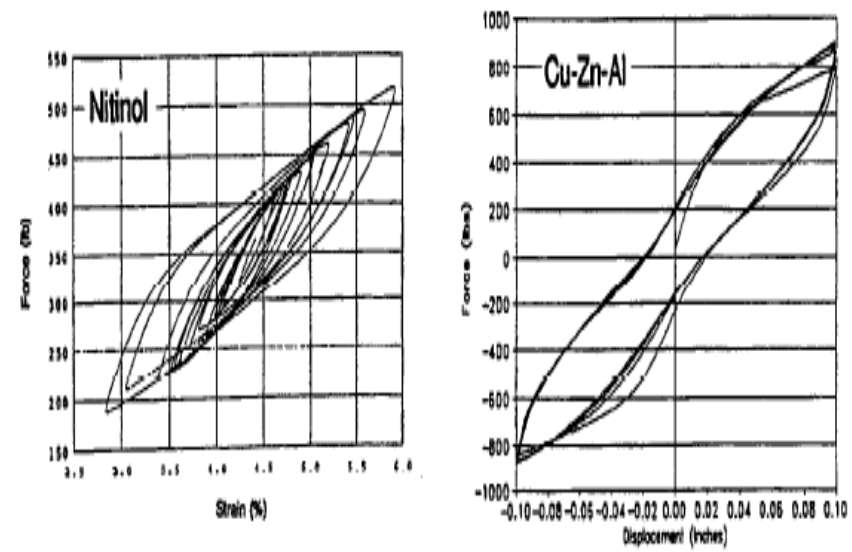

Fig. 7 Hysteresis loops for SMAs: Nitinol and $\mathrm{Cu}-\mathrm{Zn}-\mathrm{Al}$

\section{Structural Health Monitoring}

Recently with the large infra boom and huge cost incurred in construction of structures as well as the importance of these infrastructures in the socio economic benefits, it becomes necessary that such structures withstand damages to restore functioning of the society. With time, the varying loading conditions and environmental factors degrade the strength and other mechanical properties of structural system, thereby reducing their resistance capabilities and making them vulnerable to earthquakes. It hereby becomes necessary to continuously inspect and monitor the health of the structure to ensure its required mechanical properties, as at the time of construction, are intact. The concept of structural health monitoring thus provides the necessary tools for real time monitoring of structural health, using sensing technology, data transmission, actuation and stimulus response systems to either help structure self-restore its performance based properties or rectifications for the same by human intervention. This concept is actively attracting the field of civionics for embedded systems in structures using intelligent materials. This field is in close association with 
various fields like electronics, information technology, computer science, data acquisition and transmission, material science, nanotechnology and sensing technology. With the uncertainty in the occurrence of an earthquake, the ability of the structure to withstand seismic impact over its given life period remains constant, thereby establishing confidence in the structure [27, 31].

\section{SUSTAINABILITY, RESILIENCY AND ENERGY EFFICIENCY OF STRUCTURES}

The massive increase in construction and adjoining activities has raised concerns for increasing carbon footprint. A more sustainable adaption of technology for construction as well as constructed structures, usually referred to as green/sustainable structures has been initiated. It has also put forth the necessity to judiciously use resources and consume less energy in the life cycle process of materials being used. As has been stressed before it is eminent that a structure is capable of restoring its functionality and desired structural properties after the hazard has withdrawn. The necessity of a resilient structure arises from the perspective of sustainability and energy efficiency as well as safety of users and performance of structure along with intervention for disruption to smooth socio economic functionality of the society during an earthquake [28].

\section{CONCLUSION}

The various aspects of innovation for structures call for coordinated contribution among each other. Prioritizing the safety and comfort of users, and aiming towards a cost efficient, environment friendly and performance based design of structures, to meet seismic safety of structural systems is need of the time. Extensive research towards wider application of above aspects is being expected to overcome the uncertainties of seismic activities. It is suggested to adopt these advancements for seismic safety in various codes and guideline manuals by various organizations.

\section{REFERENCES}

[1] Chopra A.K. 2007. A Book on Dynamics of Structure- Theory and application to earthquake engineering, $2^{\text {nd }}$ edition. Prentice Hall of India Pvt Ltd, New Delhi.

[2] Duggal S. K., A Book on Earthquake resistant design of structure.

[3] Pankaj Aggarwal \& Manish Shrikhande; A Book on Earthquake resistant design of structures.

[4] Benson H. Tongue; A Book on Principles of vibration.

[5] Murty C.V.R., Rupen Goswami, Vijayanarayanan A.R., and Vipul V. Mehta; A Book on some concepts on earthquake behaviour of buildings.

[6] IS: 456 -2000, Code of Practice for Plain and Reinforced Concrete.

[7] IS: 13935-1993, Repair and Seismic Strengthening of BuildingsGuidelines.

[8] IS: 1893(Part-I)-2002, Criteria for Earthquake Resistant Design of Structures, Fifth Revision

[9] IS: 4326-1993, Earthquake Resistant Design and Construction of Buildings- Code of Practice (Second Revision).

[10] Pankaj Agarwal, S. K. Thakkar and R. N. Dubey. Seismic Performance of Reinforced Concrete Buildings during BHUJ Earthquake of January 26, 2001.

[11] IITK-GSDMA Guidelines for seismic evaluation and strengthening of Buildings, 2005, Indian institute of Technology Kanpur. Project sponsored by Gujarat State Disaster Mitigation Authority.

[12] IS-NBC-2005: National Building Code of India. Steps for safe design and construction of multi-storey reinforced concrete buildings.

[13] Durgesh, C. Rai, Department of Civil Engineering, Indian Institute of Technology Kanpur, Kanpur. The Gujarat State Disaster Management Authority, An over view of Earthquake Engineering

[14] S.J. Patil and G.R. Reddy. State of art review-Base isolation for structures; International Journal of Emerging Technology and Advance Engineering, Volume 2, Issue 7, July 2012; Page 438-453

[15] Alessandro Martelli; State of the art on the development and application of seismic vibration control techniques and some innovative strengthening methods for civil and industrial structures; $17^{\text {th }}$ International conference on structural mechanics in reactor technology (SMiRT 17); Prague, Czech Republic; 17-22 August 2003; Paper: K13-4.

[16] Christian Meinhardt, Daniel Siepe and Peter Nawrotzki. Seismic isolation and protection system, "Passive damping devices for earthquake protection of bridges and buildings;; The journal of ASSIS, vol II, 2011

[17] Robert J. McNamara, McNamara/Salvia. Seismic damage control with passive energy devices: A case study.

[18] Juan Enrique Martinez-Rueda; On the evolution of energy dissipation devices for seismic design; Journal of Earthquake Spectra, volume 18, no. 2, May 2002; Page 309-346. https://doi.org/10.1193/1.1494434

[19] Fahim Sadek, Bijan Mohraz, A.W. Taylor, and R.M. Chung; Passive energy dissipation devices for seismic application; NISTIR 5923, National institute of Standards and Technology, USA; November 1996.

[20] Pocanschi A., Krause O., and Haendel B. Braced steel frames with Hysteretic Dampers; Proceedings of the $9^{\text {th }}$ European Conference on Earthquake Engineering; 1990; paper-3, page no. 29-36.

[21] B.F. Spencer Jr. , T.T. Soong; new applications and development of active semi-active and hybrid control techniques for seismic and non-seismic vibration in USA; Proceedings of International Post-SMiRT conference seminar on seismic isolation, PED \& active control of vibration of structures, Cheju(Korea), 1999

[22] M.C. Constantinou, T.T. Soong, And G.F. Dargush, Passive Energy Dissipation Systems For Structural Design And Retrofit, Mceer, University at Buffalo, NY, 1998.

[23] D. Taylor and P. Duflot; Fluid Viscous dampers used for seismic energy dissipation in structures.

[24] H.T. Banks and G.A. Pinter; Damping: Hysteretic damping and models; Invited section, Encyclopaedia of vibration, 2000.

[25] M.L. Lai, P. Lu, D.A. Lunsford, K. Kasai, and K.C. Chang; Viscoelastic Damper: A damper with linear or non-linear material; $11^{\text {th }}$ world conference on earthquake engineering, 1996; Paper no. 795.

[26] B.F. Spencer Jr., G. Yang, J.D. Carlson, and M.K. Sain; Smart Dampers for seismic protection of structures: A full scale study; Proceedings of $2^{\text {nd }}$ world conference on structural control, 1998.

[27] Susmita Kamila; Introduction, classification and application of smart materials: An overview; American journal of applied sciences 10(8), page 876-880, 2013. https://doi.org/10.3844/ajassp.2013.876.880

[28] Michel Bruneau, and Andrei Reinhorn; Overview of the resilience concept. Proceedings of the $8^{\text {th }}$ US national conference on earthquake engineering; Paper no. 2040, April 2006

[29] Bhedasgaonkar, B.V. Assessment of Damage to Framed RCC Structures in Gujarat Earthquake and Retrofitting with Fibre Wrapping Technique.

[30] Subrata Chandra Das and Md. Enamul Haque Nizam; Application Of FRP Composites In Civil Engineering, International Journal Of Advanced Structures And Geotechnical Engineering, ISSN 2319-5347, Vol 3 No. 3, July 2014

[31] Foresight Smart Materials for $21^{\text {st }}$ Century Report, The Institute Of Materials, Minerals And Mining. 